\title{
Biotic carbon offset programs: sponsors of or impediment to economic development?
}

\author{
Mark C. Trexler ${ }^{1}$, Richard Meganck ${ }^{2}$ \\ ${ }^{1}$ Trexler and Associates, 1131 S.E. River Forest Rd., Oak Grove, Oregon 97267, USA \\ ${ }^{2}$ United Nations Environment Programme, Regional Coordinating Unit, Caribbean Environment Programme,
} 14-20 Port Royal St., Kingston, Jamaica, WI

\begin{abstract}
The effects of a changing climate could fundamentally disrupt critical economic progress in many developing countries. Accelerated economic development activities are often discussed as a means to mitigate long-term climate change by altering energy and environmental infrastructures to promote improved energy efficiency and reduced greenhouse gas emissions. Efforts intended to mitigate climate change could spur economic development in many sectors. However, the link between potential climate change mitigation and economic development around the world is complex. Serious consideration must be given to assess the compatıbility of climate change mitigation with economic development objectives. Biotıc global warming mitıgation measures (e.g. forest protection, reforestation, and biomass energy utilization) present a mixed picture from an economic development perspective. It has long been recognized that there is a great need for increases in investment to improve forest and resource management in developing nations; existing national and international funding does not adequately address the basic objective of sustainable productivity. Climate change mitigation is being increasingly perceived as a source of new funding for such programs. For example, if biotic mitigation mechanisms were employed to reduce or offset net global carbon emissions by 1 billion metric tons $\mathrm{yr}^{-1}$ (about $15 \%$ of the current global total) an estimated US $\$ 5$ to 10 billion could be spent annually, a significant increase in the context of current land-use and forest management expenditures in developing countries. Depending on how this money is spent, economic development prospects could be promoted or hindered.
\end{abstract}

\section{INTRODUCTION}

The potential consequences of global climate change due to increased atmospheric concentrations of several greenhouse gases are generating higher pressure for immediate implementation of technical and policy initiatives. Ultimately, existing energy production and consumption patterns in industrialized countries must be modified radically if $\mathrm{CO}_{2}$ emissions are to be significantly reduced. For developing nations, projected increases in energy consumption as well as high deforestation rates need to be reduced if global $\mathrm{CO}_{2}$ emissions are to be capped at or below current levels (IPCC 1990).

Over the long term, there is little question that the world economy will have to move away from its reliance on fossil fuels. Even with aggressive policies, however, this transition will take time. Based on economic investment in the existing energy infrastructure and on historical experience with the penetration of new technologies into the marketplace, this transition is likely to require 50 to $75 \mathrm{yr}$. During this period, preserving biotic carbon levels and enhancing biotic carbon sinks is one means to slow the accumulation of $\mathrm{CO}_{2}$ in the atmosphere.

Scientists have been evaluating the use of forestry as a means by which to respond to the threat of global warming for some time (Dyson 1977, Marland 1988, Trexler 1991, Sampson \& Hair 1992). The Noordwijk Declaration of December 1988, by establishing global targets for reversing the decline in global forest cover as a means of mitigating global warming, formalized the linkage between forestry and global warming at the political level (Ministerial Conference 1988). Since then, evaluation of forestry as a mitigation option has proceeded at all levels (NAS 1991, IPCC 1991).

The increased attention being given to forestry activities as a means to reduce net anthropogenic $\mathrm{CO}_{2}$ emissions and to enhance global carbon sinks will likely result in availability of funding for projects 
designed to offset carbon released in the energy sector. These offset projects will be located in regions where carbon can be cost-effectively sequestered or prevented from being emitted in the first place, including many developing nations. This includes countries where deforestation rates could be reduced, as well as those where land availability and climatic conditions create reforestation and other biomass accumulation opportunities. This leads to an important consideration: how will $\mathrm{CO}_{2}$ mitigation projects affect the economic development of these countries? At first glance, it is tempting to conclude that the influx of billions of dollars into the natural resource management sectors of developing nations should benefit their long-term economic development. However, the lack of experience with such projects suggests that this conclusion should be examined more closely.

This paper conceptually explores the possible link between biotic carbon offset funding and the longterm economic development objectives of developing nations. It is intended to raise issues and questions that should form the focus of a dialogue to address policy development in this area. As a conceptual think-piece, the paper does not seek to predict the future, nor does it explore all the possible variations in the mentioned scenarios. The paper first provides background information on the rationale for and the mechanisms of biotic carbon offsets in developing nations. An examination of the components that make up a 'successful' carbon offset project versus a 'successful' economic development project provides a general framework from which to analyze the overlap or divergence between the 2 objectives. As part of this discussion, existing carbon offset projects are briefly described and reviewed. Finally, several carbon offset funding scenarios and their dramatically different impacts on economic development are presented to emphasize why these issues require near-term policy attention.

\section{CARBON OFFSET APPROACHES}

Climate change mitigation can be accomplished using one or a combination of the following forestry options:

- slowing the loss or degradation of existing forests, thus preserving current carbon reservoirs (forest protection management and agricultural advances);

- increasing forest and tree cover on existing lands, thus enlarging living terrestrial carbon reservoirs (natural regeneration, reforestation, agroforestry);

- increasing the carbon stored in nonliving carbon reservoirs such as soils;

- displacing fossil fuel consumption with sustainable biomass energy sources, thus reducing net energyrelated carbon emissions.
Although all of these options are conceptually valid. each can have distinct advantages and disadvantages under different circumstances (Trexler \& Haugen 1993). Each can also have different implications for economic development goals and objectives. Because of high deforestation rates, high rates of land availability, low relative costs, and high rates of potential biomass accumulation, it is often suggested that these options can be pursued effectively in the tropics (Grainger 1988, Houghton et al. 1991, Trexler \& Haugen 1993). Slowing $\mathrm{CO}_{2}$ emissions related to land-use change, for example, is perhaps the most direct and immediate means by which to influence global warming, since forest loss and degradation combined are probably leading to the emission of between 1 and $2 \mathrm{Gt} \mathrm{C} \mathrm{yr}{ }^{-1}$ (Dale et al. 1991).

In principle, forestry efforts and other land-use practices in developing nations that would help mitigate global climate change offer an opportunity to advance 2 objectives: (1) provide funders (national governments and/or emitters of $\mathrm{CO}_{2}$ ) with an array of carbon offset projects and options, thus increasing the cost-effectiveness of an overall mitigation portfolio (Dudek \& LeBlanc 1990); and (2) provide developing nations with new funding to promote their own objectives of sustainable economic development and natural resource base maintenance and restoration. Global climate change mitigation projects can assist countries in preserving or managing their existing forest resources; restoring productive uses to degraded or abandoned lands; developing local and national supplies of wood, energy, and other economic products; and meeting the needs of poor or rural populations for a sustainable resource base and for economic growth.

\section{FUNDING CARBON OFFSETS}

Globally, climate change mitigation efforts are portrayed as a potential source of massive new funding programs for forestry and land-use management. The source of this funding will either be governmental (bilateral or multilateral) or non-governmental (private for-profit or not-for-profit firms). In today's budgetconstrained world, however, governmental funding may result more from a reallocation of spending rather than a significant net funding increase. Funding previously intended for economic development or sustainable forest management might be reassigned, for example, to a climate change mitigation budget line, even if the ultimate project being funded remains similar. It is likely, therefore, that private-sector funding presents the greatest short- to medium-term opportunity for large-scale increases in funding for 
resource management and energy sector programs intended to mitigate future climate change. This has implications for the impact of such funding on economic development, since private-sector funding is likely to be more narrowly focused on carbon sequestration objectives than public funding would be.

Large energy-producing or energy-consuming corporations in the industrialized countries are actively interested in forestry as a climate change mitigation measure both in reaction to the evolution of scientific thought regarding climate change and the growing consideration of mitigation objectives by legislative bodies. The energy sector is responsible for roughly 70 to $80 \%$ of anthropogenic $\mathrm{CO}_{2}$ emissions (Houghton et al. 1991). Without changes in current trends, the Intergovernmental Panel on Climate Change (IPCC) estimates that energyrelated carbon emissions in industrialized countries alone will increase by almost a billion metric tons within 10 yr (IPCC 1990). Most policymakers therefore perceive energy-related companies, and utilities in particular, as primary targets for greenhouse gas emission control strategies. Several kinds of emission reduction strategies are now being considered, and it appears likely that a regulatory regime to control $\mathrm{CO}_{2}$ emissions will be established relatively soon (Dornbusch \& Poterba 1992, Dower \& Zimmerman 1992). Thus, large $\mathrm{CO}_{2}$ emitting industries such as electric utilities have a significant stake in finding viable cost-saving ways to meet future emissions restrictions or avoid emissions-based fees. Forestry measures and forestry-based carbon offsets can offer these emitters an alternative that is potentially cheaper than paying a carbon tax or directly reducing their emissions.

In 1988, the AES Corporation, an independent power producer in the United States, became the first entity to initiate a voluntary $\mathrm{CO}_{2}$ offset policy based on tropical forestry. AES committed US \$ 2 million to an agroforestry and forest conservation project in Guatemala to help offset the emissions associated with a new coal-fired power plant to be built in Connecticut (Trexler et al. 1989). Today, more utilities have implemented or are investigating similar $\mathrm{CO}_{2}$ offset projects in the forestry sector (Kinsman \& Trexler 1993).

If biotic mitigation projects were to grow to the point of offsetting 1 Gt of global carbon emissions per year (some $15 \%$ of current global fossil fuel emissions), US $\$ 5$ to 10 billion probably would have to be spent annually. Combined with potential new governmental funding for global warming mitigation, this spending could dramatically increase the total resources available for forestry and land-use management efforts in developing countries.

\section{GLOBAL WARMING MITIGATION VS ECONOMIC DEVELOPMENT GOALS IN CARBON OFFSET PROJECT DESIGN}

Several variables influence how and whether a proposed carbon offset project serves the objectives of reducing the probability or magnitude of climate change. Another set of variables influences a given project's role in encouraging economic development. Under a mandated system of $\mathrm{CO}_{2}$ emissions reductions or offsets, $\mathrm{CO}_{2}$ emitters likely will be held responsible in some way for the success of projects they choose to pursue. Notwithstanding limited experience with the carbon offset concept, extrapolation from other regulatory programs can suggest criteria that ultimately will be applied to climate change mitigation projects. Criteria likely to become increasingly important to the evaluation, selection, and regulatory accreditation of projects include:

- project credibility as reflected by the conceptual ability of the project's components to actually result in incremental carbon storage from a baseline over a given period;

- long-term project reliability as evaluated by global experience with similar concepts, the background and expertise of project proponents, and relevant physical, social, economic, and political variables in the country of implementation;

- verifiability of the land-use intervention or management change claimed;

- measurability of the carbon offset credit claimed;

- cost-effectiveness as compared to alternative mechanisms for controlling greenhouse gas emissions.

\section{Designing successful carbon offset projects}

Projects specifically designed for carbon sequestration purposes should prove better able to respond to regulatory and funding concerns pertaining to conceptual validity, verifiability, and monitoring feasibility than projects designed to meet other objectives such as conservation of biological diversity or agricultural development. Several techniques can be used to maximize these desirable characteristics in a project:

- focusing on projects likely to result in new (and measurable) biomass or in measurable fossil fuel displacement;

- focusing on regions that have high biomass production and/or accumulation potentials based on climate and soils;

- focusing on project types that 'multiply' the areal effect of a particular forestry intervention (e.g. agroforestry-based firebreaks that encourage natural 
regeneration in adjacent blocks of fire-climax grasslands);

- focusing on projects that can explicitly and credibly link biomass production through agroforestry or regeneration with the protection of existing forest biomass;

- focusing on project types for which related successful experience exists in the country's forestry or resource management sector;

- focusing on project concepts that will be expandable and replicable once developed and successfully implemented;

- structuring projects to include progress milestones that allow preliminary evaluation prior to full commitment of project funding, utilize endowments to ensure long-term funding, and provide for sufficiently long implementation periods (e.g. $10 \mathrm{yr}$ or more) to assure project sustainability and carbon sequestration reliability.

Ideally such projects will be located in moist regions with good soils, low population densities, established property rights, and stable social and political systems. In reality, projects will be adapted to actual project opportunities varying in one or more respects from the ideal. Generally speaking, however, reforestation projects are less likely to be successful in the long-term sequestration of carbon when located in arid or climatologically unpredictable areas, areas with high population densities and land pressures, areas of uncertain land tenure, or areas with unstable social and political systems.

\section{Designing successful economic development projects}

Much of the need for economic development in the tropics occurs in areas characterized by aridity, climatological instability, high population densities resulting in unprecedented land pressures, uncertain land tenure, and unstable social or political systems. Economic development projects are often implemented in areas with resource bases that are seriously degraded and under tremendous pressure. Given the projected regulatory credit criteria for carbon offset projects, it will be difficult to site projects in these areas.

Furthermore, development projects are often process- rather than outcome-oriented. The process of encouraging community involvement and alleviation of suffering can be as important to project success as quantifiable deliverables. There may be little emphasis on short-term deliverables because the social attributes being promoted - education, health, income - are long-term objectives. Potential carbon offset regulatory criteria requiring verifiability and measurability of a project's carbon offset benefits can therefore conflict with the design of many economic development projects. Indeed, some organizations known for their economic development work are questioning whether to become involved with carbon offset projects precisely because they fear losing the flexibility to pursue their social and economic development objectives.

Without needing to broach the issues surrounding the concept of sustainable economic development, a significant question emerges from this discussion: to what degree can and should climate change mitigation through biotic carbon offsets be expected to advance economic development objectives in light of the potential regulatory need to provide for a credible, verifiable, reliable, and cost-effective carbon offset? This question becomes increasingly significant as the likelihood increases that large-scale funding for global warming mitigation will become available.

\section{Ongoing carbon offset projects}

Projects being considered for global climate change mitigation funding, including the few already in existence, were in most cases originally proposed as sustainable agriculture, economic development, conservation of biological diversity, or even anti-desertification projects. They have been 'recast' as carbon offset projects in an attempt to take advantage of funding now becoming available for mitigation of climate change. As a consequence, many of these projects utilize approaches that are different than might have been chosen to maximize the magnitude and reliability of long-term carbon benefits. The carbon benefits of the previously mentioned AES project, for example, are very hard to quantify precisely because the project emphasizes economic development objectives. Other ongoing projects also illustrate some of the problems of conflicting objectives in project design and implementation. Nevertheless, the very existence of these pilot carbon offset projects serves the goal of long-term reductions in atmospheric $\mathrm{CO}_{2}$. It is only through the development and implementation of a range of project types under a variety of circumstances that a thorough understanding will emerge of what really is and is not feasible in terms of long-term carbon sequestration.

Projects currently being funded for carbon offset purposes include:

- community-based afforestation in Guatemala, in which small farmers are being trained and supported in planting trees to halt erosion, increase agricultural productivity, and provide income through fuelwood, fruit, and lumber production. The carbon benefit results primarily from the protection of nearby forest associated with these measures; 
- nature reserve establishment in Paraguay, in which a forest parcel targeted for sale to timber interests and containing endangered species has been purchased and is being managed for long-term conservation;

- support of indigenous peoples in the Amazon to aid in their efforts to obtain and protect ownership rights to customary lands, and thus contribute to the long-term conservation of forests located on those lands;

implementation of 'biomass friendly' harvesting practices in Malaysia to reduce damage to the forest associated with timber extraction, including better road design and directional tree felling;

- establishment of tropical hardwood plantations on agricultural land in Ecuador; and

planting of Douglas fir on private pasture land in the Pacific Northwest of the United States.

These projects cover carbon offset possibilities rang ing from social forestry to commercial plantations. Although none of these projects has been subject to regulatory accreditation, the experience of the companies undertaking these projects illustrates the difficulty of identifying credible carbon offset projects from within the economic development project portfolio. Pertinent evaluative issues include:

- the analytical challenge that can be involved in quantifying the link, if any, between sustainable agriculture projects and forest protection (with its associated long-term carbon preservation);

- the practical difficulties involved in attributing a given amount of carbon protection or sequestration to a specific policy or financial intervention, when in fact numerous interventions of various types are occurring on an ongoing basis in order to promote project success;

- the analytical means for identifying the appropriate 'carbon baseline' against which to compare carbon offset project impacts, particularly in the environment posed by complex economic development projects;

- the conceptual difficulties involved in deciding whether to assign carbon offset credit for the implementation of land-use management practices that should already have been established with or without project funding;

- the difficulties in attempting to maximize social welfare during implementation of an economic development project while always having to worry whether the carbon offset goals under which the project was funded are being advanced or impeded; and
- the modeling requirements involved in estimating the degree to which economic projects such as plantation establishment actually add to global biomass production, as opposed to simply displacing biomass production away from somewhere else.

Overall, few of the carbon offset projects currently being funded correspond particularly well to several of the regulatory objectives previously mentioned, namely carbon offset credibility, reliability, verifiability and measurability. The next generation of offet projects, designed with variables such as these in mind, will likely be more representative of what projects will look like in the future.

\section{ALTERNATIVE OUTCOMES OF LARGE-SCALE CARBON OFFSET FUNDING}

Billions of dollars may soon become available for $\mathrm{CO}_{2}$ emissions reduction and offset efforts from industrialized countries and corporations. Based on the factors discussed above and on the perspective of the interest groups that will play a role in shaping national and international policy in this area, it is possible to suggest several plausible scenarios representing the long-term outcomes of large-scale carbon offset funding in the tropics.

\section{The 'development-as-usual' scenario}

A large amount of money could be spent on 'doing more of the same' with respect to poverty alleviation, sustainable agriculture, etc. Concurrently, population growth in developing nations could overwhelm the carbon sequestration implications of these programs, so that 20 yr later carbon would continue to be lost to the atmosphere at alarming rates through deforestation and forest degradation. Although many people might have been incrementally assisted, a net carbon loss rather than sequestration may have occurred. The international development community could be viewed as favoring this scenario, as already suggested by attempts to procure global warming mitigation funding for anti-desertification projects that may be difficult to link to significant carbon offset benefit.

\section{Land-purchasing-and-leasing scenario}

For corporations and governments concerned about long-term reliability of carbon sequestration, the option of purchasing or leasing land in developing countries may appear attractive. Direct control over the 
uses made of forest or reforestable land could appear to offer the best prospects for long-term carbon offset credibility and reliability. Many countries encourage foreign investment and allow the purchase of land by foreigners. Over 10 to $20 \mathrm{yr}$, large areas of land in tropical countries could end up owned or leased by private or public foreign entities.

This approach could result in considerable carbon sequestration. It is not clear, however, that this outcome would be considered an economic development success. Indeed, problems of migration to urban areas with resulting crowding and unemployment likely would be aggravated as people are displaced from the countryside by carbon offset projects. Nor could the political integrity of these parcels be guaranteed over the long-term; a political backlash accompanied by land nationalization would be a distinct possibility.

\section{The 'welfare' or 'incentives' scenario}

Governments anxious for international debt relief or other forms of economic assistance might be tempted to commit to large-scale forest protection or reforestation in return for economic grants or debt forgiveness. This option has already been extensively discussed as a means to achieve large-scale forest protection. Although this approach could result in the promulgation of laws, policies and programs that would protect and store considerable carbon, legitimate questions will be raised concerning the likelihood that these laws and policies would actually be implemented, that local populations would ultimately benefit from these payments or that economic development would in fact occur. In many cases governments lack the ability to actually bring about the land-use changes to which they might agree. In other cases corruption or other implementation barriers might keep the money from going to its intended destination. As a result, it is not clear that this 'welfare' approach would ultimately be considered an economic development or climate change mitigation success.

\section{The forest management scenario}

Huge areas of forest that might be deforested or severely degraded in coming decades could be managed properly in an organized fashion through the availability of large-scale carbon offset funding. Currently, the economic returns from sustainable forest management usually cannot compete favorably with short-term economic returns associated with less careful management and subsequent conversion to alternative uses (ITTO 1988, Buschbacher 1990). The potential deleterious long-term economic consequences resulting from the land's inability to support anything but forest cover over the long term is generally not considered in the short-term economic equation. By compensating for the differences in rates of economic return, large-scale carbon offset funding funneled into the forest management sector could advance goals of carbon sequestration, economic development, biodiversity protection, watershed management, and indigenous peoples' self-determination. There are, however, significant technical and implementation barriers facing large-scale natural forest management in the tropics (Johnson \& Cabarle 1993).

\section{The biomass energy scenario}

Currently, the upfront costs of planting and growing biomass crops, building an energy conversion facility (e.g. a biomass gasifier driving a combustion turbine), and installing the infrastructure needed to distribute the energy produced combine to make the pursuit of large-scale biomass energy uneconomical as compared to fossil fuels (Hall et al. 1990). There are, however, large areas of land in developed and developing nations capable of supporting sustainable biomass production at levels that would make the production of commercial energy technically feasible (Houghton 1990). As with natural forest management, large infusions of carbon offset funding could compensate for the cost difference between biomass and fossil fuel energy production. Hundreds of millions of hectares might in principle be converted to biomass energy production, storing billions of tons of carbon in new biomass and displacing the emissions of many more billions of tons of fossil fuel $\mathrm{CO}_{2}$.

Sustainable commercial biomass energy production on a large scale, however, remains a largely theoretical proposition; a great deal remains to be understood and demonstrated about the environmental and economic implications of biofuels. Additionally, no major interest group can be identified that would have a strong preference for this scenario over others. Biomass energy is a step removed from the projects conventionally promoted by either economic development or environmental interests, notwithstanding the vital role of energy supplies both to economic development and long-term environmental protection.

\section{CONCLUSIONS}

Each of the scenarios developed in this paper assumes that all carbon offset funding would be targeted in a single direction. This clearly oversimplifies what will 
likely occur, as suggested by the range of project types currently being funded for carbon offset purposes. Nevertheless, the potential offset accreditation problems associated with existing projects suggest that future carbon offset project funders will employ increasingly rigid criteria by which to evaluate potential projects as the likelihood grows that new $\mathrm{CO}_{2}$ regulatory regimes will be implemented. Indeed, the funding bias against using carbon offset monies to support the categories of economic development projects currently viewed as receiving insufficient funding is likely to be reinforced if regulators approach the issue from the same technical perspective applied to other pollution control efforts. As previously argued, this results from the fact that the most technically defensible biotic carbon offset projects are likely to be located in remote or 'safe' areas to promote reliable long-term carbon sequestration, and removed from centers of population where poverty and political instability problems are most significant.

The scenarios illustrate the potential conflicts between the economic development and carbon offset communities in spending the large sums of money that may soon become available for global climate change mitigation programs (see Fig. 1). The conflicts are intentionally exaggerated; even with respect to the 'development as usual', 'land purchase', and 'welfare' scenarios, it is possible that projects could be designed to provide a better match among competing objectives. Nevertheless, we suggest several conclusions:

(1) Massive new private-sector spending on carbon offsets in developing countries could be spent in ways having very different implications for a country's resource base, population, and economy.

(2) It should not be assurned that private-sector goals associated with gaining regulatory accreditation for carbon offset projects will correspond well to the economic development priorities of many developing nations.

(3) Certain approaches to carbon offset forestry are more likely than others to advance both global climate change mitigation and economic develop-

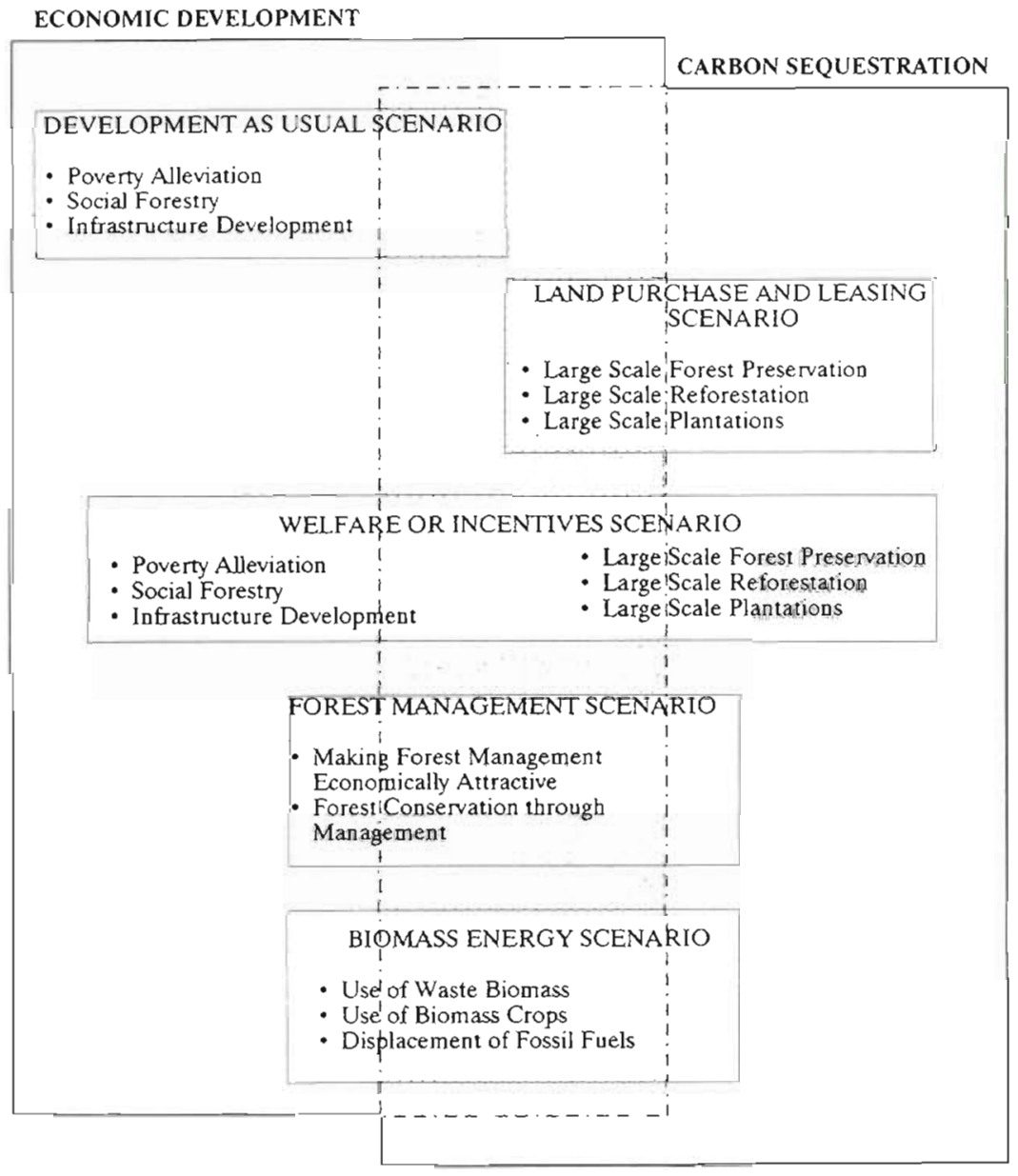

Fig. 1 Graphical representation of the extent to which stylized offset funding scenarios advance economic development and carbon sequestration goals. All the represented scenarios can advance both objectives, but certain scenarios are much more likely to do so

ment goals. Perhaps most obvious are natural forest management and the commercial utilization of biomass energy in the tropics. Both could play major roles in creating jobs and increasing national incomes, and both could be significant in reducing net anthropogenic $\mathrm{CO}_{2}$ emissions from those countries and globally. Unfortunately, neither option has a powerful advocacy group with a self-interest in promoting the option in place, and significant technical impediments remain.

(4) The economic development community, to the extent it hopes to benefit from carbon offset funding, should promote carbon offset concepts that represent a confluence between the 2 sets of objectives. This may require modification of existing priorities and funding wishlists.

(5) As public and corporate policy develops in the area of global warming mitigation, it may be that differ- 
ent kinds of carbon offset projects should be pursued by different funders. Private funders, for example, might best pursue projects specifically meeting the 5 regulator criteria previously discussed and providing for relatively secure longterm carbon benefits (e.g. forest protection, regeneration, and reforestation). Public funders might best pursue projects that have high potential payoffs for both global warming mitigation and economic development (e.g. agroforestry, social infrastructure, fuelwood supplies), but may be difficult to reliably predict and verify in terms of long-term carbon benefit.

(6) As regulators begin to provide policy guidance to private enterprises as to the regulatory criteria that will be used in granting carbon offset accreditation, the implications of each criterion should be carefully considered. By definition, carbon control and offset regulations will have to be designed in a less quantitatively rigorous manner than $\mathrm{NO}_{\mathrm{x}}$ or $\mathrm{SO}_{2}$ control regulations, which are based on emissions monitoring at the stack. $\mathrm{CO}_{2}$ emissions do not pose the short-term health and environmental impacts that $\mathrm{NO}_{\mathrm{x}}$ or $\mathrm{SO}_{2}$ emissions do.

(7) Some $\mathrm{CO}_{2}$ control measures result in dramatically more important ancillary benefits than do others. Regulators may wish to encourage private funders to undertake projects that might be difficult to quantify in terms of $\mathrm{CO}_{2}$ offset benefit, but that clearly have the potential for long-term payoffs in meeting carbon sequestration, economic development, and other policy objectives.

Regulators who undertake policy development in this area need to recognize that their treatment of these issues could dramatically affect the economies and land-use trends of developing countries around the world, as well as the long-term political viability of the carbon offset concept. It is not a regulatory task to be undertaken cavalierly.

\section{LITERATURE CITED}

Buschbacher, R. J. (1990). Natural forest management in the humid tropics: ecological, social, and economic considerations. Ambio 19(5): 253-57

Dale, V. H., Houghton, R. A., Hall, C. A. S. (1991). Estimating the effects of land-use change on global atmospheric $\mathrm{CO}_{2}$ concentrations. Can. J. For. Res. 21:87-90

Dornbusch, R., Poterba, J. M. (eds.) (1992). Global warming economic policy responses. MIT Press, Cambridge

Dower, R. C., Zimmerman, M. (1992). The right climate for carbon taxes. World Resources Institute, Washington, DC

Dudek, D. J., LeBlanc, A. (1990). Offsetting new $\mathrm{CO}_{2}$ emis- sions: a rational first greenhouse policy step. Contemp. Policy Issues 8 (July 1990): 29-42

Dyson, F. J. (1977). Can we control the carbon dioxide in the atmosphere? Energy 2: 287-91

Grainger, A. (1988). Estimating areas of degraded tropical lands requiring replenishment of forest cover. Int. Tree Crops J. 5: 31-61

Hall, D. O., Mynick, H. E., Williams, R. H. (1990). Carbon sequestration versus fossil fuel substitution: alternative roles for biomass in coping with greenhouse warming. PU/CEES Report No. 255, Center for Energy and Environmental Studies, Princeton University, Princeton, NJ

Houghton, R. A. (1990). The future role of tropical forests in affecting the carbon dioxide concentration of the atmosphere. Ambio 19(4): 204-09

Houghton, R. A., Unruh, J, Lefebvre, P. A. (1991). Current land-use in the tropics and its potential for sequestering carbon. In: International Institute for Environment and Development. Proceedings: technical workshop to explore options for global forestry management. International Institute for Environment and Development, Bangkok, p. $297-310$

IPCC (Intergovernmental Panel on Climate Change) (1990). Scientific assessment of climate change. World Meteorological Organization, Geneva

IPCC (Intergovernmental Panel on Climate Change) (1991). Climate change: the IPCC response strategies. Island Press, Washington DC

[TTO (International Tropical Timber Organization) (1988). Natural forest management for sustainable timber production. International Institute for Environment and Development, London

Johnson, N., Cabarle, B. (1993). Surviving the cut: natural forest management in the tropics. World Resources Institute, Washington, $D C$

Kinsman, J. D., Trexler, M. C. (1993). Terrestrial carbon management and the electric utility industry. Presented at: Terrestrial biospheric carbon fluxes; quantification of sinks and sources of $\mathrm{CO}_{2}$. Bad Harzburg, Germany, 1-5 March, 1993. J. Wat. Air Soil. Pollut 70: in press

Marland, G. (1988). The prospect of solving the $\mathrm{CO}_{2}$ problem through global reforestation. U.S. Department of Energy, Washington, DC

Ministerial Conference on Atmospheric Pollution and Climatic Change (1988). The Noordwijk declaration on atmospheric pollution and climatic change. Noordwijk, The Netherlands

NAS (National Academy of Sciences) (1991). Policy implications of greenhouse warming - mitigation panel. National Academy Press, Washington, DC

Sampson, R. N., Hair, D. (eds.) (1992). Forests and global change, Vol. 1, Increasing forest cover. American Forests, Washington, DC

Trexler, M. C. (1991). Forestry and global warming: the physical and policy linkages. In: Levi, B. G., Hafemeister, D., Scribnee, R. (eds.) Global warming: physics and facts. AIP Conference proceedings. Am. Inst. Physics, New York, p. 201

Trexler, M. C., Faeth, P. E., Kramer, J. M. (1989). Forestry as a response to global warming: an analysis of the Guatemala agroforestry and carbon sequestration project. World Resources Institute, Washington, DC

Trexler, M. C., Haugen, C. (1993). Keeping it green: evaluating tropical forestry strategies to mitigate global warming. World Resources Institute, Washington, DC (in press) 